\title{
Lesión osteocondral extensa de cóndilo femoral; tratamiento en un tiempo con matriz colágena y concentrado de médula ósea - reporte de un
} caso

\section{Big Osteochondral Lesion; Treatment with Collagen Scaffold and Bone Marrow Concentrate - Case Report}

\author{
Rafael Calvo R. ${ }^{1}$ David Figueroa P. ${ }^{2}$ Nelson Morales C. ${ }^{3}$ Francisco Figueroa B. ${ }^{3}$ Rafael Calvo M. ${ }^{4}$ \\ ${ }^{1}$ Traumatólogo del Equipo de Rodilla de la Clínica Alemana, \\ Universidad del Desarrollo Santiago, Santiago, Chile \\ 2 Traumatólogo, Jefe del Equipo de Rodilla de la Clínica Alemana, \\ Región Metropolitana, Santiago, Chile \\ ${ }^{3}$ Fellowship Cirugía de Rodilla de la Clínica Alemana - UDD, Región \\ Metropolitana, Santiago, Chile \\ ${ }^{4}$ Estudiante de Medicina Universidad del Desarrollo (UDD), Región \\ Metropolitana, Santiago, Chile \\ Address for correspondence Nelson Morales C., MD, Clínica Alemana \\ de Santiago, Avda. Vitacura 5951, Región Metropolitana, Chile \\ (e-mail: nelsonmc@vtr.net). \\ Rev Chil Ortop Traumatol 2017;58:100-105.
}

\section{Resumen \\ Palabras Clave \\ - lesión condral \\ - células mesenquimáticas \\ - médula ósea \\ - parche colágeno \\ - osteocondral \\ - microfractura \\ - transplante osteocondral autólogo \\ - osteocondritis}

El tratamiento de las lesiones osteocondrales de gran tamaño y profundidad resultan un desafío debido a que las técnicas habituales (microfractura o transplante osteocondral autólogo), son insuficientes para cubrir el defecto; eso es particularmente importante en pacientes jóvenes, pues se debe intentar técnicas que generen la menor comorbilidad posible. Presentamos un caso de un paciente de 18 años con una lesión osteocondral de $6 \mathrm{~cm}^{2}$ por $14 \mathrm{~mm}$ de profundidad, tratado mediante autoinjerto óseo, concentrado de médula ósea y matriz colágena, con resultados satisfactorios tanto en lo funcional como en lo imagenológico. Esa técnica presenta la ventaja de realizarse en un tiempo y con una fuente de células troncales mesenquimáticas (Médula ósea), validada en la literatura y altamente reproducible. received

January 23, 2017

accepted

November 27, 2017
DOI https://doi.org/

$10.1055 / \mathrm{s}-0037-1615254$. ISSN $0716-4548$.
Copyright @ 2017 by Thieme Revinter

Publicações Ltda, Rio de Janeiro, Brazil
License terms

(c) $(1) \$$ 
Abstract

\section{Keywords}

- osteochondral lesions

- mesenchymal stem cells

- bone marrow

- collagen patch

- osteochondral

- micro fracture

- autologous osteochondral transplant

- osteochondritis
The treatment of large osteochondral defects represent a challenge, because the common techniques used (micro fracture or osteochondral autologous transplantation) are insufficient to cover the defect; this is particularly important in young patients where we expect the least comorbidity. We report a case of an 18-yearold patient with an ostechondral injury of $6 \mathrm{~cm}^{2}$ and $14 \mathrm{~mm}$ deep, treated with bone autograft, bone marrow concentrate and a matrix of collagen with satisfactory functional and images results. This technique has the advantage to be performed in one single time and with a source of mesenchymal stem cells (bone marrow) validated in the literature.

\section{Introducción}

El manejo de las lesiones osteocondrales, sigue siendo unos de los mayores desafíos en la práctica de cualquier traumatólogo. Eso se debe a que el cartílago es un tejido altamente especializado y con propiedades biomecánicas muy particulares, lo que sumado a su escaso poder de reparación, se traduce en dolor y un pobre desempeño en las actividades del paciente si esas lesiones no son tratadas adecuadamente. ${ }^{1}$

Las estrategias clásicas para intentar reparar lesiones focales de cartílago, dependiendo del tamaño y profundidad de la lesión y de si existe o no compromiso del hueso subcondral, incluyen: debridamiento; estimulación de la médula ósea (microfracturas); técnicas basadas en células, solas (ACI) o con uso de diferentes matrices (MACI), y el uso de injertos osteocondrales autólogos o alogénicos para los de mayor tamaño. ${ }^{2,3}$ La selección de cada una de esas técnicas, dependerá de características propias del paciente tales como la edad, el tipo de actividad física y de manera muy importante, de las características propias de la lesión (geometría, tamaño, ubicación) y de la articulación (alineamiento, estabilidad, indemnidad meniscal). ${ }^{4}$ Pero la gran interrogante es qué técnica usar en las lesiones mayores a $4 \mathrm{~cm}^{2}$, y mayores de $1 \mathrm{~cm}$ de profundidad. A lo anterior, agregamos la inquietud de intentar solucionar todo en un mismo acto quirúrgico, disminuyendo la morbilidad y los costos para el paciente.

A continuación presentamos una opción de tratamiento ya descrita previamente, que se considera biológica y que incluye el uso de concentrado de médula ósea, lo que aportaría células troncales mesenquimáticas además de factores de crecimiento; éstos, protegidos por una matriz colágena impermeable a las células, maximizando el contacto entre ellas, y generando un ambiente "condrogénico," que estimularía la diferenciación celular. ${ }^{5,6}$

\section{Reporte del Caso}

Esquiador de sexo masculino de 18 años, sin alteración de alineación de extremidades inferiores ni inestabilidad articular; y sin comorbilidad. Consulta por primera vez en 2007 por cuadro clínico e imagenológico compatible con una osteocondritis disecante del cóndilo femoral medial, inestable; en ese momento se le aconsejó tratamiento quirúrgico el cuál rechazó. En 2013 consulta nuevamente por presentar reagudización de sus síntomas sin mediar trauma directo, presentando al examen derrame y bloqueo articular.

Estudio de imágenes; La teleradiografía de extremidades inferiores no evidenció mal alineamientos; la radiografía simple y resonancia magnética (-Fig. 1) de la rodilla derecha demostraron una gran lesión osteocondral compatible con una osteocondritis disecante grado $\mathrm{V}$ del cóndilo femoral medial, inestable, contenida y en zona de carga. Se observan dos fragmentos; uno libre y otro en el lecho del defecto. El área comprometida era de $6 \mathrm{~cm}^{2}$ y de $14 \mathrm{~mm}$ de profundidad. No presentaba lesión de los ligamentos cruzados, meniscos, compartimientos femorotibial y femoropatelar.

En el contexto de un paciente joven, deportista competitivo, con una lesión osteocondral de gran tamaño se optó por una opción que permitiera preservar el resto de la superficie articular del cóndilo medial. Se planificó la cirugía pensando en aportar sustento al lecho del defecto para recuperar altura con un autoinjerto de hueso esponjoso de cresta iliaca, aportar concentrado de médula ósea de cresta iliaca del paciente, obtenida mediante punción y sistema de centrifugado, a modo de aporte biológico, y utilizando un parche de matriz colágeno I/III (Chondro-Gide ${ }^{\circledR}$ Geistlich Pharma AG)

En un primer tiempo, se obtuvo un autoinjerto de hueso esponjoso de cresta iliaca, $3 \mathrm{~cm}$ por detrás de la espina iliaca anterosuperior, y se extrajo por punción de médula ósea de la 


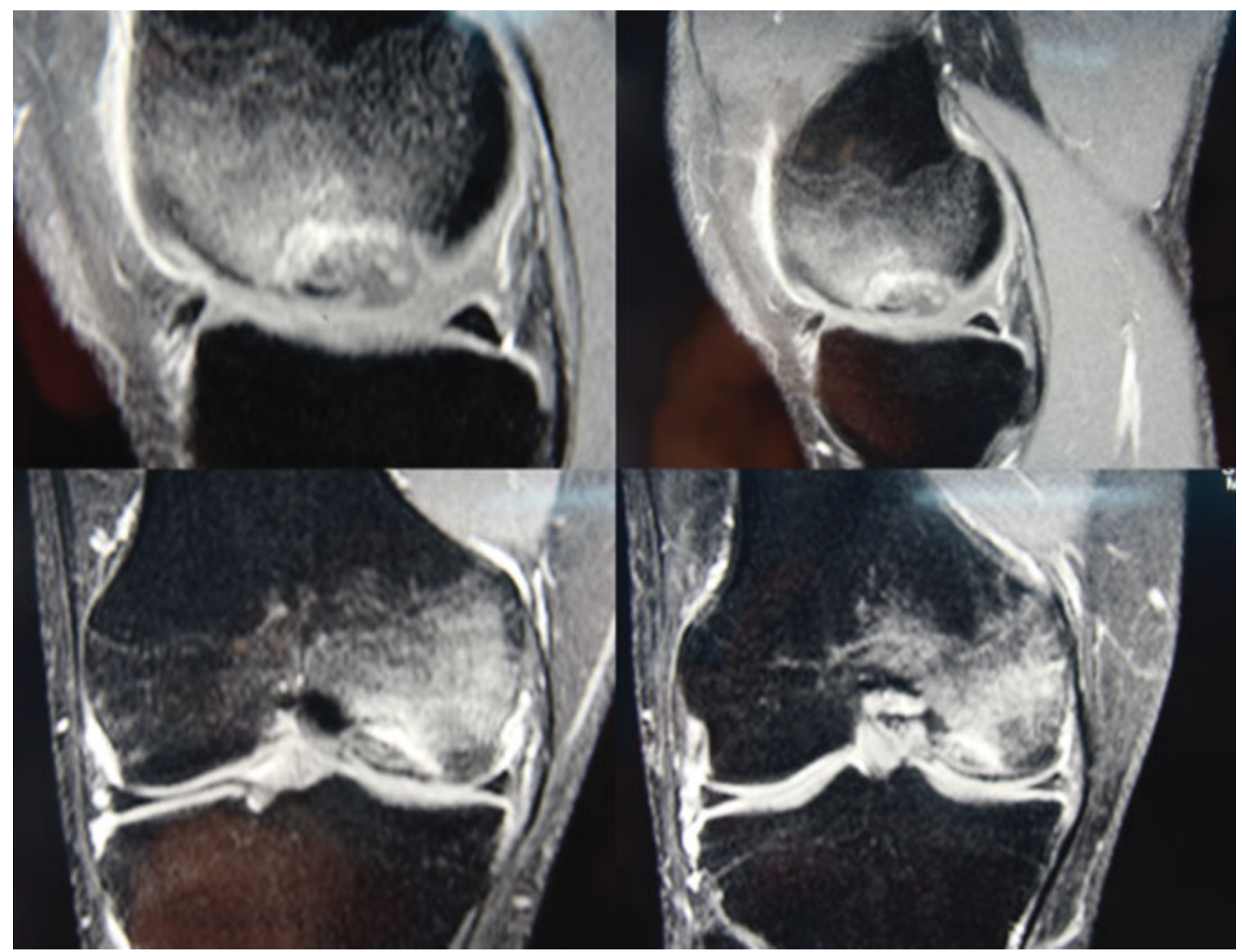

Fig.1 Resonancia Magnetica que muestra en diferentes cortes la lesión osteocondral de gran tamaño, y con importante reacción ósea adyacente.

misma zona, para obtener un concentrado mediante centrifugación. La técnica consiste en obtener $60 \mathrm{ml}$ de médula ósea aspirada de cresta iliaca con un kit de punción y aspiración, (Marrowstim ${ }^{\circledR}$ Biomet), el cual posteriormente se centrifuga a 3200rpm durante 15 minutos, lo que incrementa la concentración de las células mononucleares de la médula ósea de 4 a 6 veces el valor inicial (no se realizó conteo celular); otros $5 \mathrm{ml}$ de sangre periférica se centrifugan durante 5 minutos a igual número de revoluciones para obtención de trombina.

En un segundo tiempo del mismo acto quirúrgico, y luego de realizar una artroscopia diagnóstica, se realizó una artrotomía parapatelar medial. Al acceder a la articulación se identifican los fragmentos osteocondrales. Ellos se encontraban redondeados, de aspecto antiguo y el cartílago impresionaba desvitalizado. Se resecaron sin dificultad. Se cruentó el lecho de la lesión y se realizaron perforaciones. Se rellenó el lecho con el autoinjerto de hueso esponjoso morcelizado e impactado y se cubrió con el parche de colágeno suturado a los bordes de la lesión, mediante puntos transóseos separados. Finalmente inyectamos el concentrado de médula ósea bajo ese parche, sellando con Tissucol (sellador de fibrina - Baxter) (-Fig. 2).

La rehabilitación del paciente consideró una férula ROM desde la salida de pabellón solo a modo de protección, pues no se restringieron grados de flexión o extensión; se indicó uso para deambular y dormir exclusivamente. Las actividades kinésicas comenzaron en el post operatorio inmediato; 2 visitas kinesiológicas diarias, durante las 48hrs de hospitalización, en las que se educó ejercicios isométricos y de rango articular; se educó marcha con dos bastones, descarga completa de la extremidad operada, lo que se mantuvo invariable hasta las 8 semanas de post operado. Pasado ese tiempo, se retiró en forma definitiva la férula ROM y se permitió carga parcial de 10\% a 20\% del peso corporal en forma progresiva hasta llegar a $40 \mathrm{Kg}$ a las 12 semanas retirando 1 bastón. El retiro definitivo de bastones se realizó aproximadamente a las 16 semanas. A partir de ese período, se intensificó el trabajo de fortalecimiento y el reintegro deportivo, hasta los 6 meses, momento en que se indicó el alta, basado en los hallazgos de evolución clínicos y de resonancia magnética.

Tras 26 meses de seguimiento, las imágenes de RM postoperatorias (-Fig. 3 ), muestran un adecuado relleno e integración del defecto, así como tejido reparativo que a pesar de tener algunas irregularidades, presenta una morfología adecuada de baja señal en todas las secuencias propias del fibrocartílago. Consideramos que dado que se trata de fibrocartílago, en ese caso el uso de T2 mapping no sería un aporte. A 2 años de evolución el paciente ha retomado el esquí de forma competitiva y realiza fútbol de forma recreacional, refiriendo dolor solo ocasional; lo anterior se objetiva claramente en un aumento en Score de Lysholm; de 82 puntos iniciales a 95 puntos.

\section{Discusión}

Los objetivos del tratamiento de las lesiones osteocondrales incluyen la disminución del dolor, mejorar las funciones de vida diaria y al menos retrasar la aparición de un fenómeno degenerativo que motive la indicación de una artroplastia de 


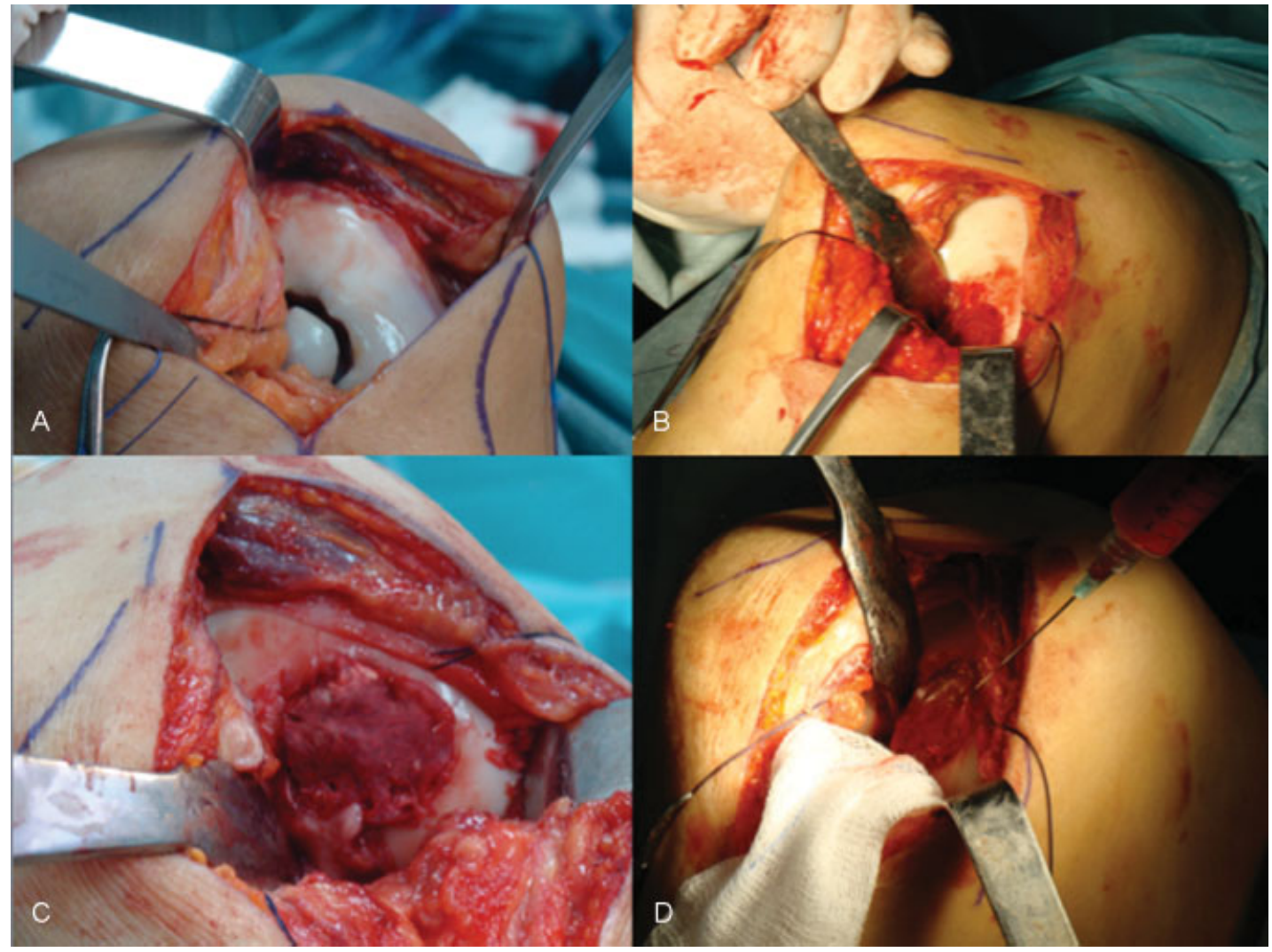

Fig. 2 (A) Lesión osteocondral. (B) aporte de autoinjerto de cresta iliaca. (C) Matriz colágena cubriendo la zona de defecto. (D) Aporte de concentrado de médula ósea.

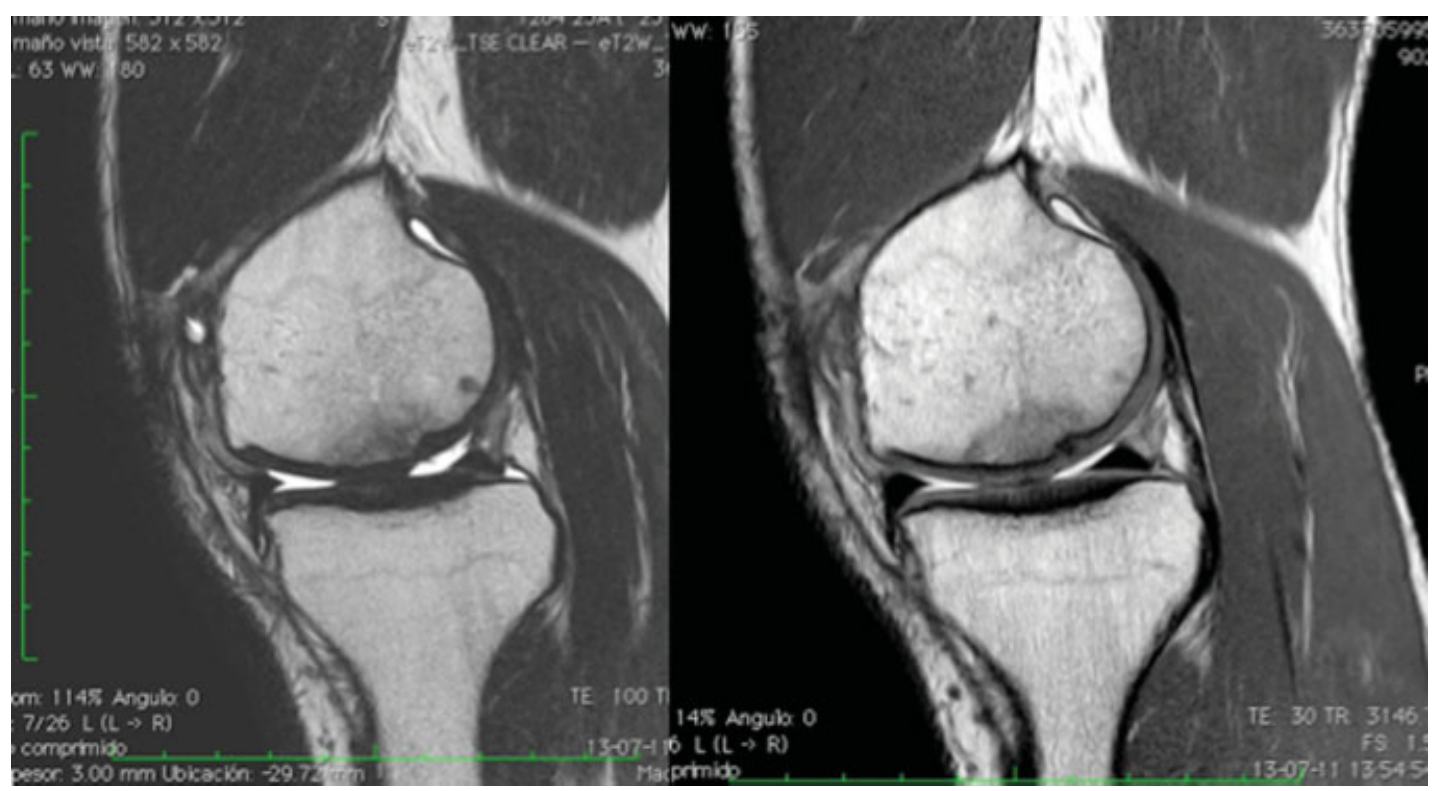

Fig. 3 Imagen de control de 2 años posterior a la cirugía. Se evidencia irregularidad en zona posterior, pero cubierto por tejido de intensidad similar al cartílago.

rodilla. Las técnicas actuales disponibles para tratar esas lesiones incluyen la micro/nano fractura, el transplante osteocondral autólogo, la mosaicoplastía, la implantación autóloga de condrocitos (ACI/MACI) y el uso de diferentes matrices ..$^{3,7}$ Actualmente, las investigaciones en ciencias básicas han adicionado al arsenal terapéutico el uso de células mesenquimáticas pluripotenciales, ingeniería de tejidos y la terapia génica. ${ }^{8}$

Un desafío aún mayor significa el tratamiento de las lesiones osteocondrales de gran tamaño, pues casi indefectiblemente, se traducen en un deterioro de la calidad de vida de los pacientes por síntomas en sus actividades de vida diaria y más aún en la 
eventual práctica deportiva. Para esos casos, existe la posibilidad de usar un aloinjerto osteocondral de gran tamaño; que si bien ha reportado buenos y excelentes resultados en el $70 \%$ de los pacientes a largo plazo, ${ }^{9}$ presenta algunas limitantes técnicas, tales como la necesidad de usar aloinjertos frescos, la posibilidad de transmisión de enfermedades, la integración del injerto, el adecuado "match" entre el sitio donante y el receptor; y un alto costo económico. Otra alternativa adecuada a considerar en nuestro caso, dice relación con el uso de la implantación autóloga de condrocitos (ACI/MACI); sin embargo esta técnica obliga a realizarla en 2 tiempos lo que también aumenta los costos; un primer tiempo artroscópico para la obtención de condrocitos viables y un segundo tiempo abierto para la implantación de dichas células luego de un par de semanas de expansión. Ese procedimiento además, puede presentar complicaciones descritas como la falla, delaminación o la hipertrofia del tejido perióstico (ACI de primera generación), esa última descrita para el $15-30 \%$ de los casos, lo cual podría sumar un 3er evento quirúrgico. ${ }^{10}$

Si bien presentamos un solo caso, creemos posee la ventaja de ser realizada en un mismo acto quirúrgico, además de combinar conceptos mecánicos (autoinjerto hueso esponjoso - sustrato - y membrana colágena I/III - barrera estabilizadora) como biológicos (Células Mesemquimaticas Pluripotenciales MSC). A. Gobbi describió un tratamiento similar en 15 pacientes con un promedio de edad de 48 años (32 a 58), reportando los mejores resultados en lesiones de menor tamaño, y en aquellas lesiones únicas; ${ }^{5}$ a diferencia de lo que nosotros presentamos, no se utilizó autoinjerto en esos 15 pacientes.

El parche colágeno I/III (Chondro-Gide ${ }^{\circledR}$ Geistlich Pharma AG) es elaborado a partir de colágeno porcino, y es naturalmente reabsorbido por acción de colagenasas. Tiene un rol fundamental en concentrar el aporte celular en la zona de lesión y aportar la estabilidad necesaria para movilizar precozmente al paciente, además de permitir un ambiente óptimo para la diferenciación celular. Es considerado un tratamiento de segunda generación con estudios que reportan buenos resultados a 5 y 7 años en asociación con microfracturas para defectos mayores de $2 \mathrm{~cm}^{2}{ }^{11,12}$ Comparado con el parche perióstico (primera generación), tiene menos tasas de complicaciones (inferiores al $8 \%$ ), fundamentalmente asociados a la cosecha e hipertrofia de ese último. ${ }^{10}$ Otras matrices biológicas de los que se han descrito, destacan el Hialuronato (HA) que contribuye a la migración celular y a la diferenciación celular, siendo una molécula ideal para la ingeniería de tejidos. Marcacci ha descrito el uso de HA al cual aporta condrocitos autólogos para generar una matriz tridimensional, eliminando la necesidad de un parche (tercera generación). ${ }^{13}$ Chitosan es un polisacárido lineal compuesto primordialmente de poliglucosamina, que está cargado positivamente y es trombogénico. Dentro de sus propiedades destaca ser biodegradable, biocompatible y de alta adhesividad. Se ha descrito que la adición de b-glicerofosfato (GP) produce un gel de Chitosan termosensible, que es líquido a temperatura ambiente, pero solidifica a temperatura corporal, transformándolo en un excelente scaffold inyectable (BST-CarGel; BioSyntech, Laval, Quebec, Canadá) Hoemann informó que el tratamiento con esta matriz (BST-CarGel) mejoró las características del tejido hialino de reparación en comparación con los controles microfracturas. ${ }^{14,15}$

Dentro de los polímeros sintéticos biodegradables destacan el ácido poliláctico (PLA), el ácido poliglicólico (PGA) y el Poliláctico-co-glicólico (PGLA), los que se caracterizan por tener una hidrólisis aleatoria de sus cadenas Éster, pudiendo liberar subproductos tóxicos para el ambiente condral circundante.

Se ha demostrado que el uso de MSC, tiene buena adherencia a matrices colágenas, especialmente las obtenidas de médula ósea por sobre las obtenidas de tejido graso, además de ser más fácil y rápida su obtención. Respecto si debemos expandir o no nuestro concentrado de MSC, además de considerar las implicancias técnicas y económicas entre realizarlo o no, se ha descrito en la literatura que el proceso de expansión podría ocasionar pérdida del fenotipo condrogénico, hay riesgo de contaminación de la muestra y perdida de propiedades paracrinas de las MSC obtenidas de médula ósea sobre otras líneas celulares. Además de lo anterior, no hay diferencias significativas en el potencial condrogénico u osteogénico en ambos grupos $^{16,17}$

\section{Conclusión}

Presentamos un caso de lesión osteocondral tratado con una técnica simple, fácilmente reproducible y realizada en un solo acto quirúrgico; lo que sumado a los muy buenos resultados clínicos del paciente, la transforman además en un procedimiento altamente costo efectivo. Se requieren más estudios con mayor número de casos y seguimiento prospectivo para recomendar con evidencia adecuada la realización de esta técnica.

\section{Conflictos de Intereses}

No existen conflictos de interés de los autores para este trabajo. No existe financiamiento para esta publicación.

\section{References}

1 Mankin HJ. The response of articular cartilage to mechanical injury. J Bone Joint Surg Am 1982;64(03):460-466

2 Kerker JT, Leo AJ, Sgaglione NA. Cartilage repair: synthetics and scaffolds: basic science, surgical techniques, and clinical outcomes. Sports Med Arthrosc Rev 2008;16(04):208-216

3 Ozmeriç A, Alemdaroğlu KB, Aydoğan NH. Treatment for cartilage injuries of the knee with a new treatment algorithm. World J Orthop 2014;5(05):677-684

4 McNickle AG, Provencher MT, Cole BJ. Overview of existing cartilage repair technology. Sports Med Arthrosc Rev 2008;16 (04):196-201

5 Gobbi A, Karnatzikos G, Scotti C, Mahajan V, Mazzucco L, Grigolo B. One-Step Cartilage Repair with Bone Marrow Aspirate Concentrated Cells and Collagen Matrix in Full-Thickness Knee Cartilage Lesions: Results at 2-Year Follow-up. Cartilage 2011;2(03):286-299

6 Gianakos AL, Sun L, Patel JN, Adams DM, Liporace FA. Clinical application of concentrated bone marrow aspirate in orthopaedics: A systematic review. World J Orthop 2017;8(06):491-506

7 Bedi A, Feeley BT, Williams RJ III. Management of articular cartilage defects of the knee. J Bone Joint Surg Am 2010;92(04): 994-1009 
8 Michael W. Kessler, MD, MPH, George Ackerman, MD, Joshua S. Dines, MD,w and Daniel Grande, PhD. Emerging Technologies and Fourth Generation Issues in Cartilage Repair. Sports Med Arthrosc Rev 2008;16:246-254

9 Emmerson BC, Görtz S, Jamali AA, Chung C, Amiel D, Bugbee WD. Fresh osteochondral allografting in the treatment of osteochondritis dissecans of the femoral condyle. Am J Sports Med 2007;35(06): 907-914

10 Wood JJ, Malek MA, Frassica FJ, et al. Autologous cultured chondrocytes: adverse events reported to the United States Food and Drug Administration. J Bone Joint Surg Am 2006;88(03):503-507

11 Volz M, Schaumburger J, Frick H, Grifka J, Anders S. A randomized controlled trial demonstrating sustained benefit of Autologous Matrix-Induced Chondrogenesis over microfracture at five years. Int Orthop 2017;41(04):797-804

12 Schiavone Panni A, Del Regno C, Mazzitelli G, D’Apolito R, Corona $\mathrm{K}$, Vasso M. Good clinical results with autologous matrix-induced chondrogenesis (Amic) technique in large knee chondral defects. Knee Surg Sports Traumatol Arthrosc 2017
13 Marcacci M, Kon E, Zaffagnini S, et al. Autologous chondrocytes in a hyaluronic acid scaffold. Oper Tech Orthop 2006;16:266-270

14 Chenite A, Chaput C, Wang D, et al. Novel injectable neutral solutions of chitosan form biodegradable gels in situ. Biomaterials 2000;21 (21):2155-2161

15 Hoemann CD, Hurtig M, Rossomacha E, et al. Chitosan-glycerol phosphate/blood implants improve hyaline cartilage repair in ovine microfracture defects. J Bone Joint Surg Am 2005;87(12): 2671-2686

16 Wise JK, Alford AI, Goldstein SA, Stegemann JP. Comparison of uncultured marrow mononuclear cells and culture-expanded mesenchymal stem cells in 3D collagen-chitosan microbeads for orthopedic tissue engineering. Tissue Eng Part A 2014;20(1-2): 210-224

17 Kohli N, Wright KT, Sammons RL, Jeys L, Snow M, Johnson WE. An In Vitro Comparison of the Incorporation, Growth, and Chondrogenic Potential of Human Bone Marrow versus Adipose Tissue Mesenchymal Stem Cells in Clinically Relevant Cell Scaffolds Used for Cartilage Repair. Cartilage 2015;6(04):252-263 